\section{A comunicação integrada de marketing no ciberespaço: as características do ambiente virtual que são favoráveis à integração da comunicação organizacional*}

\section{The integrated marketing communication in cyberespace: the characteristics of the virtual enviroment that are favorable for the integration of organizational communication}

\section{Resumo}

No século XXI, os Chief Executive Officers (CEO) de organizações, de um modo geral, descobriram que, além de cuidar de processos administrativos e operacionais para obterem resultados, teriam que, necessariamente, investir em comunicação organizacional para que a cultura da instituição e os valores desta impregnassem no produto/serviço, reforçando a imagem organizacional. Diante da tecnologia da informação, que, atualmente, evolui, com o advento das redes sociais no ambiente virtual, uma forma otimizada de realizar este incremento de imagem seria, por exemplo, adotar as características comuns que a comunicação integrada de marketing e o ciberespaço possuem de modo a tornar este último um ambiente de trânsito rotineiro para a execução da comunicação organizacional protagonizada pelas assessorias de relações públicas, assessoria de publicidade/propaganda e assessoria de imprensa de forma integrada dentro de redes computadorizadas. Este artigo aborda que pontos comuns podem estabelecer conexões entre ambos os aspectos analisados e conclui que esses pontos são as características de convergência e sinergia, atuando com o objetivo de atingir o diferencial de imagem pretendido.

Palavras-chave: Imagem organizacional. Ciberespaço. Comunicação Integrada de Marketing. Convergência. Sinergia.

\begin{abstract}
In the twenty-first Century, the Chief Executive Officers (CEO) of organizations, in general, found that, besides taking care of administrative and operational processes to achieve results, they would have to necessarily invest in organizational communication so that the culture of the institution and their values could permeate their product/service, enhancing the organizational image. Given the Information Technology that is currently evolving with the advent of social networking in the virtual environment, an optimized way to accomplish this increase of image would be, for example, adopting the common characteristics of the integrated marketing communications and cyberspace in the order to make the latter aspect a routine traffic environ-
\end{abstract}

\footnotetext{
* Artigo recebido em ?/20?? Aprovado em ?/20??

1 Oficial da Marinha do Brasil, atualmente cursando especialização em Gestão da Comunicação nas Organizações no UniCEUB. Email: sahdemattos@gmail.com.
} 
ment for the implementation of organizational communication played by public relations advisory, advertising/ marketing advisory and media relations advisory in an integrated manner within computer network. This article discusses common points that can establish connections between both aspects analyzed and concludes that these points are convergence and synergy, acting in order to achieve the desired differential of image.

Keywords: Organizational image. Cyberspace Integrated Marketing. Communication. Convergence. Synergy.

\section{Introdução}

No século XXI, as principais empresas e organizações possuem um Planejamento Estratégico ${ }^{2}$ com preocupações, à medida que os mercados tornam-se mais interligados e interdependentes, na área de promoção, que está, por sua vez, dentro do Marketing. ${ }^{3}$ A Comunicação Integrada de Marketing ${ }^{4}$ (CIM) é uma expansão da vertente promoção, dentro do mix de marketing (produto, promoção, preço e praça). Ela é o reconhecimento da importância de comunicar as mesmas mensagens com conteúdos complementares para os mercados-alvo; nesta comunicação, há uma tendência de sobreposição de mensagens. O fim maior é impregnar o produto ou serviço na imagem da organização, agregando, com isso, o valor da

2 O Planejamento estratégico organizacional ocupa o topo da pirâmide organizacional. É responsável pelas grandes decisões estratégicas que envolvem as organizações como um todo. Caracteriza-se como de longo prazo e em constante sintonia e interação com o meio ambiente. Visa buscar as melhores formas para gerenciar as ações estratégicas das organizações, tendo por base as demandas sociais e competitivas, as ameaças e oportunidades do ambiente, para que a tomada de decisões no presente traga os resultados mais eficazes possíveis no futuro (KUNSCH, 2003, p. 214).

3 Segundo a definição atual da American Marketing Association (AMA), "Marketing é uma atividade organizacional e um conjunto de processos para criar, comunicar e entregar valor e gerenciar relacionamento com clientes, mantendo benefícios para a organização e para seus públicos de interesse (os chamados stakeholders)" (OGDEN; CRESCITELLI, 2007, p. 1).

4 A comunicação Integrada de "Marketing" (CIM) é definida como uma filosofia que direciona a convergência das diversas áreas (de comunicação organizacional) permitindo uma atuação sinérgica. Pressupõe uma junção da comunicação institucional, da comunicação mercadológica e da comunicação interna que formam o mix, o composto da comunicação organizacional (KUNSCH, 2003, p. 150, grifo nosso). marca $^{5}$ institucional ao produto/serviço. Cada uma das variáveis da CIM afeta o programa de marketing da organização, de modo que, para garantir resultados financeiros e o cumprimento de metas estratégicas, todas essas variáveis devem ser gerenciadas pelo profissional de marketing ou de comunicação de forma cooperativa. Portanto, sem um plano de marketing, não se pode estabelecer um planejamento de comunicação, pois a CIM faz parte do Marketing (OGDEN; CRESCITELLI, 2007, p. 3). Logo, resumindo, a promoção, atualmente, confunde-se com a CIM (PINHEIRO; GULLO, 2009, p. 185). É importante lembrar que, com isso, a comunicação, juntamente com outros esforços e elementos de marketing (produto, preço e praça), contribui, no caso de empresas, para gerar as vendas e o lucro para sustentar seus próprios investimentos, para remunerar o capital aplicado pela empresa ou organização em seus negócios e suas atividades, bem como, contribui para a obtenção dos recursos necessários para sua sobrevivência e crescimento sustentável (PINHEIRO; GULlO, 2009, p. 260). Assim, há o atendimento direto à missão e às demandas estratégicas organizacionais de modo a atingir as metas aprovadas pelos líderes (presidentes, ou, simplesmente, "Chief Executive Oficers" CEO) (CORRÊA, H.; CORRÊA, C., 2008, p. 5).

Ao comunicar suas mensagens, as organizações passaram, também, a ter um olhar voltado, de forma crescente, para a interdependência de mercados, com a evolução da tecnologia dos computadores. Para tanto, essas organizações usam ferramentas de comunicação organizacional, tais como a internet ${ }^{6}$ e o comércio eletrônico nas lojas virtuais (PINHEIRO; GULLO, 2009, p. 9). Essa afirmativa encontra respaldo em Manuel Castells (1999, p. 16):

\footnotetext{
5 Segundo a definição atual da American Marketing Association (AMA), marca é um nome, termo, símbolo, desenho ou uma combinação desses elementos que deve identificar os bens ou serviços de um fornecedor ou grupo de fornecedores e diferenciá-los da concorrência. Portanto, tecnicamente falando, sempre que um profissional de marketing cria um novo nome, logotipo ou símbolo para um novo produto, ele cria uma marca (KELLER, MACHADO, 2006, p. 2).

6 A internet [rede mundial de computadores] é uma iniciativa estadunidense de âmbito mundial encetada, com apoio militar, por empresas de informática financiadas pelo governo estadunidense para criar um clube mundial de usuários de computadores e bancos de dados. Tem características de topologia aleatória de redes locais de fanáticos por informática e um sistema tarifário anárquico de serviços incontroláveis (SCHEER, 1994 apud CASTELLS, 1999, p. 428).
} 
É por isso que, observando a mais de uma década as tendências emergentes do que agora assumiu a forma de uma revolução na comunicação, apresentei, na primeira edição desse livro, a hipótese de que uma nova cultura estava se formando, a cultura da virtualidade real, na qual redes digitalizadas de comunicação multimodal passaram a incluir de tal maneira todas as expressões culturais e pessoas a ponto de terem transformado a virtualidade em uma dimensão fundamental de nossa realidade (grifo nosso).

Essa virtualidade, como nova dimensão, fez-se sentir, em termos de importância, quando uniu um aspecto antigo, as redes de relacionamentos sociais, (PINHEIRO; GULLO, 2009, p. 285), a um aspecto novo, que são as tecnologias digitais de formação de redes sociais e organizacionais (CASTELLS, 1999, p. 4). Com essas tecnologias digitais e o consequente controle dos meios de produção de serviços baseados no conhecimento, houve uma revolução nas tecnologias de comunicação, que se intensificou nos últimos anos.

As redes de computadores no chamado ciberespaço, ${ }^{7}$ os softwares ${ }^{8}$ de código aberto (chamados de livres por não serem pagos direitos a seus autores, inclusive os protocolos de internet) e a capacidade de comutação e transmissão digital nas redes de telecomunicação acarretaram a expansão da internet, após sua privatização na década de 1990, e a grande generalização de seu uso em todos os campos de atividade (CASTELLS, 1999, p. 9). Nessa mesma década, outra revolução nas comunicações aconteceu em todo o mundo: a explosão da comunicação sem fio, com uma capacidade crescente de conectividade e largura de banda em gerações sucessivas de telefones celulares. Alie-se a isso o fato de que a internet, a "World Wide Web" 9 (www), e a comunicação sem fio não

7 Ciberespaço definido como "[...] o espaço de comunicação aberto pela interconexão mundial dos computadores e das memórias dos computadores" (LÉVY, 1999, p. 92).

8 Software é conjunto de procedimentos, regras e métodos de programação e exploração de computadores e equipamentos de um sistema informático. Sequência de instruções codificadas que, quando acessadas devidamente, fazem com que o computador execute determinadas funções. Parte não tangível da máquina. Diz-se, também, programa de computador ou conjunto de programas (RABAÇA; BARBOSA, 2001, p. 688).

9 A "World Wide Web" é uma função da internet que junta, em um único e imenso hipertexto ou hiperdocumento (compreendendo imagens e sons), todos os documentos e hipertextos que a alimentam. Hipertexto, por sua vez, é um texto em formato digital, reconfigurável e fluido. Composto por blocos elementares ligados por links que podem ser explorados em tempo real na tela (LÉVY, 1999, p. 27). são mídias no sentido tradicional. São, antes, os meios para a comunicação interativa. No entanto, as fronteiras entre meios de comunicação em massa e todas as outras formas de comunicação estão perdendo a nitidez (CASTELLS, 1999, p. 10-11).

Essa diminuição de nitidez introduzida pela internet gerou um espaço virtual, no sentido apresentado por Castells; uma nova dimensão a ser considerada, pois a CIM pode vir a se beneficiar, de forma contínua, dessa revolução nas tecnologias de comunicação com algumas conexões de características comuns a esta, com o ambiente do ciberespaço a ser explorado pelas suas três áreas componentes. Assim, para analisar a relação entre a CIM e o ciberespaço, o presente artigo tem o objetivo de estabelecer as potencialidades deste ambiente virtual, a serem utilizadas pela CIM, de modo a proporcionar ferramentas para um "salto de imagem" da organização, utilizando-se de suas partes componentes: relações públicas, publicidade e propaganda e assessoria de imprensa para alcançar as metas estratégicas organizacionais.

Para alcançar o objetivo proposto, procedeu-se à pesquisa documental e bibliográfica, com consulta a fontes primárias: autores que abordam o tema com suas obras revisadas e atualizadas em CIM e no ciberespaço, de modo a possibilitar uma agregação de pontos de vistas comuns que possam efetuar uma ligação construtiva do primeiro com o segundo tema. A delimitação temporal aborda o estado da arte em evolução de ambos os temas, mormente no advento do século XXI, no qual essa nova fronteira virtual se abre como uma nova possibilidade para os profissionais de comunicação. Dessa forma, esses profissionais podem obter sucesso nas estratégias de comunicação que formulam em suas respectivas organizações (PINHEIRO; GULLO, 2009, p. 261).

\section{0 gradual surgimento do ciberespaço}

O termo "Ciberespaço" foi inicialmente cunhado por Wiliam Gibson, em 1984, em seu romance de ficção “Neuromante” e é definido por Pierre Lévy (1999, p. 92) como "o espaço de comunicação aberto pela interconexão mundial dos computadores e das memórias dos computadores".

Dentro do ciberespaço está inserida uma cultura chamada de cibercultura, que é definida como a expres- 
são da aspiração de construção de um laço social, que não seria fundado nem sobre "links" territoriais, nem sobre relações institucionais, nem mesmo sobre as relações de poder, mas sobre a reunião em torno de redes sociais, que se confundem com os grandes centros populacionais, de centros de interesses comuns, ${ }^{10}$ sobre o jogo, sobre o compartilhamento do saber, sobre a aprendizagem cooperativa e sobre processos abertos de colaboração (LÉVY, 1999, p. 130). Da galáxia de Gutenberg (1398-1468), ${ }^{11}$ como expressão de um domínio de mídia, passando pela galáxia de McLuhan (1911-1980), ${ }^{12}$ vivencia-se, hoje, o surgimento, de forma intensa, da Comunicação Mediada por Computadores (CMC), das redes sociais e das comunidades virtuais. ${ }^{13}$ Formando o que Castells (1999, p. 431) chama de "Constelação da Internet".

Neste ciberespaço, o "apetite" para as comunidades virtuais encontra um ideal de relação humana desterritorializada, colaborativa, transversal e livre, no qual estas são os motores, os atores, a vida diversa e surpreendente do universal por contato (LÉVY, 1999, p 130).

${ }^{10}$ As pessoas estão passando a se reunir virtualmente em grupos de interesse, em vez de seguirem os critérios de proximidade geográfica ou compartilhamento de uma mesma referência social ou institucional. O resultado é um abalo na hegemonia da cultura de massa, que nos projeta na era dos nichos de consumo e das escolhas individuais, da liberdade, variedade e riqueza de expressão (RUDIGER, 2011, p. 55).

${ }^{11} \mathrm{O}$ que a TV (televisão) representou, antes de tudo, foi o fim da galáxia de Gutenberg, ou seja, de um sistema de comunicação essencialmente dominado pela mente tipográfica e pela ordem do alfabeto fonético. [...] Marshall McLuhan tocou um acorde universal quando, com toda a simplicidade, declarou que "o meio é a mensagem" [...] É por isso que Neil Postman (1931-2003), importante estudioso de veículos de comunicação, acha que a televisão representa uma ruptura histórica com o espírito tipográfico (CASTELLS, 1999, p. 417).

${ }^{12}$ A difusão da televisão nas três décadas após a Segunda Guerra Mundial (em épocas diferentes e com intensidade variável, dependendo do país) criou uma nova galáxia de comunicação, permitindo-me usar a terminologia de McLuhan - a galáxia de McLuhan (CASTELLS, 1999, p. 415).

${ }^{13}$ Comunidade virtual é um grupo de pessoas se correspondendo mutuamente por meio de computadores interconectados (LÉVY, 1999, p. 27).
Logo, desde as primeiras calculadoras programáveis: do $\mathrm{ENIAC}^{14}$, que foi considerado o primeiro computador até o advento dos computadores pessoais, inicialmente idealizados de forma bastante embrionária, por Steve Jobs (1955-2011) e Steve Wozniak (1050-), ${ }^{15}$ e do aparecimento da primeira rede de computadores, de cunho estritamente militar, a ARPANET, ${ }^{16}$ do Departamento de Defesa Estadunidense, prenunciou-se a criação da chamada "rede das redes". A universalidade da linguagem digital, então recém surgida, e a pura lógica das redes do sistema de comunicação geraram as condições tecnológicas para a comunicação horizontal, que se tornaria, com o passar do tempo, de amplitude global. Sua evolução para a ARPA - internet, que seria denominada, logo em seguida, de internet, permaneceu sustentada pelo Departamento de Defesa e operada pela National Science Foundation (NSF). Somente após as pressões do meio acadêmico, pressões comerciais e o crescimento das redes de empresas privadas e de redes cooperativas sem fins lucrativos é que, em 1995, houve a privatização total da internet (CASTELLS, 1999, p. 82-83). Outro marco para o advento do computador foi a descoberta dos circuitos integrados (CI) digitais por meio da alteração

${ }^{14}$ Os primeiros computadores começaram a surgir durante a década de 1940, ainda utilizando válvulas. Sem dúvida, o computador mais famoso daquela época foi o ENIAC (Electronic Numerical Integrator Analyzer and Computer), construído em 1945. O ENIAC era composto por nada menos do que 17.468 válvulas, ocupando um galpão imenso. Porém, apesar do tamanho, o poder de processamento do ENIAC é "ridículo" para os padrões atuais, suficiente para processar apenas 5.000 adições, 357 multiplicações e 38 divisões por segundo, bem menos até do que uma calculadora de bolso atual, das mais simples (MORIMOTO, 2005, p. 1).

${ }^{15}$ Steve Jobs e Steve Wozniak romperam com este conceito [computadores como máquinas de emprego nas empresas e burocracias públicas, que só raramente interessavam a um público mais abrangente] no final dos anos 1970, ao decidirem abandonar o amadorismo doméstico que caracterizara os primeiros experimentos com microcomputação. Para eles, chegara a hora de converter o computador em aparelho de uso doméstico comercial e, com isto, surgiu um novo ciclo que, apoiado nas redes existentes, criou as bases materiais para o aparecimento de comunidades virtuais ou processos de comunicação mediados pelos computadores (CMC), logo encampados, também, por empresas privadas como a CompuServe (1980/1982) e a "America on Line" (AOL 1985/1989) (RUDIGER, 2011, p. 16-17, grifo nosso).

${ }^{16}$ A ARPANET foi assim chamada devido à ARPA - Agência de Projetos de Pesquisa Avançada do Departamento de Defesa Estadunidense. Entrou em funcionamento em $1^{\circ}$ de setembro de 1969 (CASTELLS, 1999, p. 82). 
das características dos materiais semicondutores, ${ }^{17}$ como a Silício (Si) e o Germânio (Ge), de forma significativa, pela adição de certos átomos de impurezas ao material semicondutor relativamente puro. Essas impurezas, embora acrescentadas na proporção de uma parte para dez milhões, podem alterar a estrutura de bandas do elétron suficientemente para mudar totalmente as propriedades elétricas do material. Um material semicondutor que tenha sido submetido a este processo sofreu o que se chama de dopagem. Assim, o chamado "chip" de Silício pode substituir vários transistores e ter, em seu interior, vários circuitos lógicos, fazendo com que a integração de grandes componentes eletrônicos, em uma pastilha de Silício, diminuísse o tamanho do computador para, em um tempo posterior, torná-lo um item portátil (BOYLESTAD; NASHELSKY, 1984, p. 6). As vantagens associadas aos sistemas a semicondutor em comparação com aqueles a válvulas são: a miniaturização; o fato de serem os primeiros mais leves; e a não necessidade de pré-aquecimento.

Essa evolução natural dos computadores gerou o aparecimento do que, daí então, foi passando a ser o ambiente virtual. As tecnologias digitais afirmaram-se com sua convergência de atividades virtuais, a partir da privatização da internet, como a infraestrutura, o pilar de sustentação do ciberespaço, como o novo espaço de comunicação, de sociabilidade, de organização sinérgica e de transação, mas também o novo mercado da informação e do conhecimento (LÉVY, 1999, p. 32). Isso gerou as condições que podem fazer com que a CIM, hoje, tenha o olhar voltado para o acolhimento que este ambiente virtual pode proporcionar a seus resultados.

\section{A sinergia: o primeiro potencial de conexão com a CIM}

A importância da comunicação organizacional integrada reside no fato de ela permitir que se estabeleça uma política global, em função de uma coerência maior entre os diversos programas comunicacionais, de todos os setores e de um comportamento organizacional que tem como principal característica a homogeneidade, além

\footnotetext{
${ }^{17}$ Um material é denominado de semicondutor quando possui um nível de condutividade elétrica em algum ponto entre os extremos de um isolante (condutividade muito baixa) e um condutor, tal como o Cobre $(\mathrm{Cu})$ que possui um nível de condutividade elétrica alta (BOYLESTAD; NASHELSKY, 1984, p. 1).
}

de se evitar sobreposições de tarefas (KUNSCH, 2003, p. 180). Estas preocupações que a CIM enseja fazem com que haja uma similaridade com o ambiente virtual em relação às tarefas homogêneas e à linguagem comum deste novo ambiente. A CIM possui uma arquitetura que valoriza a sinergia conseguida com as atividades de comunicação social. No caso, estas atividades são de comunicação (interna, mercadológica e institucional), e a convergência ocorre com os seus instrumentos de atuação (relações públicas, publicidade/propaganda institucional e a assessoria de imprensa) inseridos nos meios de comunicação (KUNSCH, 2003, p. 166). Esta arquitetura também encontra identidade, mais que na convergência tecnológica, na convergência em rede que o ciberespaço proporciona a seus utilizadores e nas tendências de aumento dos usos sociais em rede, crescimento de potência e abrangência, redução nos custos e padronização de linguagem (LÉVY, 1999, p 32-33). O ciberespaço, por isso, torna-se bastante permeável e flexível para atuação da CIM.

A CIM deve expressar uma visão de mundo, que é a visão da organização, e transmitir os valores intrínsecos, não se limitando à divulgação de produtos ou serviços da organização. Deve contribuir, por meio de uma sinergia da comunicação institucional, mercadológica, e interna, para a construção de uma identidade corporativa forte e sintonizada com as novas exigências (digitais, por exemplo) e com as necessidades da sociedade contemporânea (organização em redes sociais, por exemplo). Trata-se de uma gestão coordenada e sinérgica dos esforços humanos e organizacionais, com vistas à simultaneidade de ações de comunicação e à eficácia, evitando, com isso, a duplicidade de esforços (KUNSCH, 2003, p. 180). No ciberespaço, a sinergia origina-se no esforço constante e multifacetado para melhorar, gradativamente, a comunicabilidade da rede e constitui um notável exemplo de como a produtividade de cooperação tecnológica, através da rede, acabou por aperfeiçoá-la, causando uma uniformidade da mensagem digital e uma base para a coordenação simultânea das mensagens deste espaço (CASTELLS, 1999, p. 441). Logo, tem-se que:

[...] a comunicação de todos os tipos de mensagens no mesmo sistema [virtual], ainda que este seja interativo e seletivo (sem dúvida, exatamente por isso) induz em uma integração de todas as mensagens em um padrão cognitivo comum. [...] Todas as expressões culturais, da pior à melhor, da mais elitista à mais popular, vêm juntas nesse universo digital que liga, em um supertexto histórico gigantesco, as manifes- 
tações passadas, presentes e futuras da mente comunicativa. Com isto, elas constroem um novo ambiente simbólico. Fazem da virtualidade nossa realidade (CASTELLS, 1999, p. 458, grifo nosso).

Encontra-se na integração das mensagens, proporcionada pelo ciberespaço, um exemplo para que a sinergia dos esforços humanos, na CIM, se faça com a formatação sinérgica e integrada das logomarcas e mensagens em um padrão cognitivo comum e complementar de uma mídia em relação à outra, dentro de cada job. ${ }^{18}$ Isso é análogo à sinergia que o ciberespaço proporciona a seus usuários. A natural consequência desta apresentação da organização de forma complementar em cada job é que a imagem da organização torna-se de conhecimento do público-alvo de forma interativa, apresentando-a, gradualmente, de mídia em mídia, com o padrão cognitivo comum e com o foco nas virtudes da organização, fixando nos "corações e mentes" a imagem detalhada da organização. Isso porque, na sinergia de mensagens, não se pode esquecer, por fim, que a comunicação integrada é fruto de uma constatação de mercado: "Não se pode dissociar a imagem do produto do conceito de empresa” (DIÁRIO POPULAR, 1983, p 2-19 apud KUNSCH, 2003, p. 181).

\section{A convergência: o segundo potencial de conexão com a CIM}

Outro aspecto comum entre a CIM e a virtualidade do espaço digital é a convergência. Na visão empresarial, a convergência é um processo ao mesmo tempo corporativo, de cima para baixo, e de consumidores, de baixo para cima:

[...] A convergência corporativa coexiste com a convergência oriunda do cotidiano. As empresas de comunicação estão aprendendo como acelerar o fluxo de conteúdos através de canais de entrega, a fim de expandir suas oportunidades de receita. Os consumidores, por sua vez, estão aprendendo a usar as tecnologias de co-

${ }^{18} \mathrm{Job}$ é o termo, em língua inglesa, designativo, em comunicação, da tarefa ou conjunto de tarefas relativas a um determinado trabalho, em agência de trabalho ou birô (RABAÇA; BARBOSA, 2001, p. 402). Um dos instrumentos de controle de tarefas é o cronograma. O cronograma nada mais é que "um plano que especifica os períodos de tempo nos quais as atividades (jobs) têm que ser executadas" (HAMPTON, 1980, p. 127 apud KUNSCH, 2003, p. 224). No cronograma, os jobs têm seu início e fim, seus responsáveis, e seu detalhamento de execução (KUNSCH, 2003, p. 226). municação para por os fluxos de comunicação sob maior controle e interagir com outros consumidores (JENKINS, 2009 p. 18 apud RUDIGER, 2011, p. 31).

A CIM enseja uma filosofia que a caracteriza. Esta filosofia consiste na convergência das orientações que as organizações, seja por terceirização ou por meio de seus departamentos de comunicação, devem dar à tomada de decisões e à condução das práticas de todas as suas ações comunicativas (as chamadas tarefas ou “jobs”) (KUNS$\mathrm{CH}, 2003$, p. 179).

Em cada tarefa, há uma assessoria líder que é responsável pela convergência de esforços das demais assessorias sobre a tarefa ou sobre o produto resultante. As assessorias de relações públicas, publicidade e propaganda e de imprensa estão sendo desafiadas a serem capazes de fornecer serviços integrados de comunicação e a fazerem alianças estratégicas para ter condições de atender às demandas dos seus clientes. Tal esforço pode levar a uma maximização de lucro por minimização de custos (KUNSCH, 2003, p. 182). O trabalho global do gestor de comunicação dentro da organização tem uma otimização e uma convergência de esforços dos profissionais de cada assessoria componente, quando da aplicação da divisão das tarefas em jobs, nas quais, alternadamente, há uma assessoria líder que coordena as ações das demais assessorias dentro da referida tarefa.

Para a coordenação das tarefas de forma convergente, no ambiente virtual, a CIM emprega a característica de convergência ${ }^{19}$ proporcionada pela organização em rede que o ciberespaço acolhe e que, por sua vez, é até mesmo mais importante que a própria convergência de tecnologia:

A hipótese de partida para a caracterização do
sistema de mídia na sociedade atual é que, ao
contrário do que muitas vezes sugerido, o que
o caracteriza não é a convergência tecnológica,

\footnotetext{
${ }^{19}$ Utilizando uma sugestão de McLaughlin, pode-se descrever convergência como o modo de superar as barreiras tecnológicas, econômicas e institucionais, possibilitado pelo advento das tecnologias digitais, que subdividiam a mídia em quatro grandes setores: o editorial, dominado pelo setor privado de imprensa e tutelado pelo copyright; o dos transmissores, isto é, das redes de distribuição que englobam o setor postal e de telecomunicações e internet; o do broadcasting, baseado na publicidade; e o do hardware, baseado na produção e distribuição de aparelhos destinados à comunicação (das câmeras de vídeo a estéreos, fitas e periféricos) (ORTOLEVA, 2004 apud CARDOSO, 2007, p. 16). 
mas sim a sua organização em rede. Esta organização ocorre em diversos níveis, desde o da relação tecnológica, à organização econômica e à adequação social (ORTOLEVA, 2004 apud CARDOSO, 2007, p. 16).

Desse modo, conclui-se que a convergência em rede passa a ser um fator de semelhança que aproxima a ambiência virtual das necessidades de convergência de esforços na CIM. Estes esforços, tarefas ou jobs podem fluir em uma rede de trabalho interna em que o aperfeiçoamento do produto desejado pode receber aperfeiçoamentos estruturais, modificações de conteúdo e críticas postadas em rede de computadores por parte de qualquer assessoria ou stakeholders. Pode-se, até mesmo, postar a tarefa de modo que um permissionário avulso possa contribuir com ideias aditivas a uma referida tarefa.

Adicionalmente, conclui-se que, com as características abordadas de sinergia e de convergência, bem como suas semelhanças de atuação tanto na CIM como no ciberespaço, guardadas suas utilizações específicas em ambas as matérias, estas duas características constituem-se fatores de aproximação que podem ser explorados pela assessoria de relações públicas, pela assessoria de publicidade e propaganda e pela assessoria de imprensa das organizações com vistas a fazer com que o composto ou mix de comunicação organizacional possa atuar dentro da virtualidade do ciberespaço, proporcionando o diferencial de atuação que pode vir a melhorar a imagem da organização e gerar um diferencial de credibilidade para o atendimento das metas fixadas no planejamento estratégico.

\section{Considerações finais}

A pesquisa mostra que os dois aspectos do ciberespaço abordados: a sinergia e a convergência são lições que a CIM deve observar. A CIM deve efetuar as suas tarefas, ou jobs, sob a forma de redes computadorizadas, com a assessoria líder como mediadora da rede virtual em cada job para conseguir o resultado esperado.

Adicionalmente, a CIM deve fazer com que a utilização da integração das mensagens, no ambiente virtual, em todos os produtos, se faça com a formatação sinérgica e integrada das logomarcas e mensagens em um padrão cognitivo comum e complementar de uma mídia em relação à outra. Essas ações proativas podem vir a se constituir em um diferencial de apresentação da imagem organizacional de forma organizada, integrada, completa, gradual e sem duplicidades. Isso é análogo ao que o ciberespaço proporciona a seus usuários.

As redes constituem uma nova morfologia social que a CIM deve aprender a utilizar. A difusão da lógica das redes modifica de forma substancial a operação de cada assessoria da CIM, bem como o resultado dos processos de comunicação, produtivos e de experiência, poder e cultura, tendo o ciberespaço como a base material para a sua expansão no tecido mercadológico (CASTELLS, 1999, p. 565).

Os empreendimentos destas mudanças de visão de emprego das coordenações das áreas da CIM fazem com que a imagem da organização se torne de conhecimento do público-alvo de forma interativa, apresentando-a, gradualmente, de mídia em mídia, e com o padrão cognitivo comum, com o foco nas virtudes e na imagem detalhada da organização.

\section{Referências}

BOYLESTAD, Robert; NASHELSKY, Louis. Dispositivos eletrônicos e Teoria de Circuitos. Tradução de Roberto Moura Sales. Rio de Janeiro: Prentice-Hall, 1984.

CAMPOS, Augusto. O que é software livre. Florianópolis: BR-Linux, mar. 2006. Disponível em: <http://br-linux. org/linux/faq-softwarelivre>. Acesso em: 6 set. 2011.

CARDOSO, Gustavo. A mídia na sociedade em rede: filtros, vitrines, notícias. Rio de Janeiro: Editora FGV, 2007.

CASTELLS, Manuel. A sociedade em rede: a era da informação: economia, sociedade e cultura. Tradução de Roneide Venancio Majer. 6. ed. São Paulo: Paz e Terra, 1999. v. 1.

CORRÊA, Henrique L.; CORRÊA, Carlos A. Administração de produção e operações. São Paulo: Atlas, 2008.

KELLER, Kevin Lane; MACHADO, Marcos. Gestão estratégica de marcas. Tradução de Arlete Simille Marques. São Paulo: Pearson Prenticce Hall, 2006.

KUNSCH, Margarida M. K. Planejamento de relações públicas na comunicação integrada. 4. ed. São Paulo: Summus, 2003.

LÉVY, Pierre. Cibercultura. Tradução de Carlos Irineu da Costa. São Paulo: Editora 34, 1999. 
MORIMOTO, Carlos E. ENIAC. Hardware, jun. 2005. Disponível em: <http://www.hardware.com.br/termos/ eniac>. Acesso em: 26 ago. 2011.

OGDEN, James R; CRESCITELLI, Edson. Comunicação integrada de marketing: conceitos técnicas e práticas. Tradução de Cristina Bacellar. 2. ed. São Paulo: Pearson Prenticce Hall, 2007.

PINHEIRO, Duda; GULLO, José. Comunicação integrada de marketing: gestão de elementos de comunicação: suporte às estratégias de marketing e de negócios da empresa: fundamentos de marketing e visão de empresa. São Paulo: Atlas, 2009.
RABAÇA, Carlos Alberto; GUSTAVO, Guimarães Barbosa. Dicionário de Comunicação. 2. ed. Rio de Janeiro: Elsevier, 2001.

RUDIGER, Francisco. As teorias da cibercultura. Porto Alegre: Sulina, 2011. 